\title{
Junior Lecturers as Reflective Practitioners: Minimization of Negative Comments during Evaluation of Teaching and Learning at an Institution of Higher
}

\author{
Mr Malatji K.S \\ University of Fort Hare \\ Email: KMalatj@ufh.ac.za
}

\section{Doi:10.5901/mjss.2014.v5n11p95}

\begin{abstract}
This paper investigated the practice of self-reflection by junior lecturers at an institution of higher learning in South Africa in the Eastern Cape Province. The aim of this study was to investigate the practice self-reflection by junior lecturers in one faculty, with the aim of minimizing negative comments during evaluation of teaching and learning. The researcher used qualitative research approach in this study with case study research design. Population consisted of junior lecturers. The sample consisted of 10 junior lecturers, and data were collected using open-ended questionnaires and one on one interview. During first phase of data collection 10 junior lecturers volunteered to answer open-ended questionnaires. Thereafter, purposive sampling was used to select the total of five junior lectures with less than five years teaching experience to participate on one on one interview. Themes were identified and analysed in a qualitative approach. The results of this study revealed that selfreflection is important for junior lecturers as novices in academic field because it helps them to improve their teaching practice and minimise negative comments in their teaching profession. The study recommends that junior lecturers be trained and workshopped about different approaches to reflective practices and their importance. Furthermore, the study suggests that junior lecturers should perceive self-reflection as an ongoing thing that goes along with their teaching practice; as a result they will grow and improve as professionals.
\end{abstract}

Keywords:A reflective practitioner, Professional growth, Critical reflection, junior lecturers, evaluation, teaching and learning.

\section{Background and Introduction to the Study}

The use of self-reflection gives lecturers opportunity to explore, contemplate, and analyse experiences in the classroom. This means that it helps them to track their daily activities and see to it if they are achieving their goals as academics/lecturers. Kolb (1999: 24) emphasizes these experiences as a cyclical process through stages: (1) observing oneself as a lecturer, (2) thinking about the observed experience to gain understanding and meaning of what is happening, and (3) applying the insights gained to future teaching experiences. Reflection helps individuals improve their actions and professional practice. According to Zeicher and Liston (2005:19), "reflection is also a means by which practitioners can develop a greater level of self-awareness about the nature and impact of their performance." This awareness of one's performance makes individuals think about and mull over their experiences, classroom activities and leads to improved practice. Lecturers use reflection to facilitate their own teaching as well as for the facilitation of students' learning.

Reflection requires the ability to analyse and prioritize issues, to use tacit and resource-based knowledge, and to develop a feasible plan of action. Clarke (1995:18) suggests that reflection is not about a single event in time, but occurs over time as lecturers begin to construct meaning for them. Two types of reflection facilitate lecturers' teaching: reflectionin-action and reflection-on-action (Kottkamp, 1990: 66). Reflection-in-action occurs during the activity; the activity is reshaped while in progress. Reflection-on-action occurs either following an activity or when an activity is interrupted; a retrospective thinking about an experience.

Reflection requires the ability to analyse and prioritize issues, to use tacit and resource-based knowledge, and to develop a feasible plan of action. Clarke (1995) suggests that reflection is not about a single event in time, but occurs over time as lecturers begin to construct meaning for them. Reflective practitioners take responsibility (Dewey, 1997b). Reflective practitioners consider and accept the consequences of their decisions and the changes they make in teaching style, in the learning environment, or in the university culture. Furthermore, reflective lecturers are sincere as they closely investigate their teaching (Dewey, 1997b). They take reflection seriously. Their reflection is purposeful and exciting because it helps them better understands who they are as academics and how they can be more effective. Reflective lecturers are interested in the subtleties of the art and science of teaching. They want to learn all they can about teaching from both theory and practice. They think deeply about their course work and about how it should impact their teaching. 


\section{Theoretical Framework}

For the theoretical framework, Gibbs' (1998) reflective cycle model was used in this study. According to this model reflective teaching improves lecturers' critical thinking and understanding of what they have taught (Park \& Kastanis, 2009). Junior lecturers get benefits from reflective practice in terms of deep understanding of their strengths and weaknesses and identification of underlying values, possible insufficiencies, and areas for improvement (Henderson, Napan \& Monteiro, 2004). In other words, reflective learning aims to reinforce deep learning and practice, not to focus on reflection itself. This means that the use of reflective practice does not only benefit lecturer (professional development), but also students.

\section{Application of the Model in the Context of Tertiary Education}

\subsection{Description}

In this stage of reflective cycle, a lecturer should think about the lesson and what happened. This is the important stage that provides them with opportunity to identify both their weaknesses and strengths. In the context of tertiary teaching and learning, the lecturer can think about how the lesson was introduced, how key aspects were clarified, and the level of students' participation and responses of questions by students. According to Zeichner and Liston, (2005) reflection is a means by which practitioners can develop a greater level of self-awareness about the nature and impact of their performance.

\subsection{Feelings}

After thinking about what happened in the classroom, it is also important to consider one's thinking and feeling during the time the lecture took place. One of the competencies of good practice is educator as a reflective practitioner. According to this competency, lecturers/teachers need to think about their teaching while they teach. This competency allows them to change their teaching approach if they find it not working. According to Gibbs', (2008) model it is important for lecturer to think about their feelings and what they were thinking during the time of the lesson; and these will help them to gather important information about their practice.

\subsection{Evaluation}

The concept of evaluation can be broad in the education fraternity, but in the context of Gibbs' model refers to one looking at what good or bad about their experience as novice academics. Brookfield, (1995) presented four lenses of evaluation that include peer evaluation, student evaluation, literature and self-evaluation. With regard to peer evaluation, a lecturer may choose any of his/her to assist in evaluation of his teaching, while on the other hand student evaluation gives students that lecturer is teaching an opportunity to evaluate on his teaching. The lecturer may also use literature to evaluate his teaching by reviewing what literature says about his teaching. Last a lecturer may decide to use selfevaluation that may be biased at times; however self-evaluation requires someone who is fair and eager to grow in his profession or practice.

\subsection{Analysis}

In this stage of reflective cycle, according to Gibbs (1998) lecturers try to analyse and make sense out of the situation. Analysis should include both strength and weakness, and there should be a space for development. According to Kottkamp (1990) reflection brings about an understanding of practice and is a way practitioners may learn from their experience.

\subsection{Conclusion}

In this stage lecturers conclude all processes of reflection, and in their conclusion they should also try to think of other alternatives that can help them to improve in their practice. Schon, (1987) describe a reflective practitioner as not just skilful or competent, but a thoughtful, wise, and contemplative teacher. 


\subsection{Action plan}

This is the last stage of reflective cycle, whereby lecturer will think about the entire process and be able to plan in case if the problem may arise again. According Clarke (1995) reflection requires the ability to prioritise issues, to use tacit and resource-based knowledge, and to develop a feasible plan of action.

\section{Statement of the Problems}

The practice of self-reflection assists individuals to identify their weaknesses and improve their practice. However, it appears that junior lecturers at the university under study do not reflect on their practice because they are not aware of the importance of self-reflection. As a result, they are unable to identify their weak points in their teaching practice and these results into many negative comments during the evaluation of teaching and learning.

\section{Research Questions}

In order to achieve the aim of this study, the researcher developed the following research questions:

- What are the practices of junior lecturers on self-reflection?

- What are lecturer's opinions with regard to self-reflection?

- What measures could be put in place to assist junior lecturers in enhancing self-reflective practices in performing their duties?

\section{Research Methodology}

\subsection{Research Paradigm}

The paradigm used in this study was the qualitative approach. The purpose of qualitative research is to develop an understanding of individuals and events in their natural state, taking into account the relevant context (Leedy, 2001:91). Qualitative research is predicted on the assumption that each individual, each culture and each setting is unique. In qualitative research, interpretation of data was done by means of set exterior in order to determine an amount of quality to the understanding of findings (Kolb, 1999:3). Procedures are not strictly formalized, scope is more likely to be undefined, and a more philosophical mode is adopted (Mouton \& Marias, 1998:166). Therefore this study was epitomized as qualitative research. It can be epitomized as qualitative because:

- The study was conducted in a natural setting in which the lecturers were given an open-ended questionnaires to answer questions based on self-reflection. An open-ended questionnaire was be used because the researcher wants to gather in-depth information about lecturers' views; feelings and how they practice selfreflection.

- An important concern of qualitative researchers is the meaning of human behaviour and experience. In this study the researcher was interested in the practice of self-reflection by junior lecturers,

- The data collected emanated from interviews; and did not follow numerical or statistical procedures. Thus the focus of this proposed study was on understanding and meaning through verbal narratives rather than through numbers,

- The data was gathered and analysed by qualitative methods; small groups are normally investigated in qualitative research (Van Der Westhuizen, 1999:127). In the context of study the participants consisted of junior lecturers, and this was considered as a small group.

The researcher used the qualitative methodology because he required in-depth information in order to explain junior lecturer's practices on self-reflection.

\subsection{Research Design}

The research design to be used in this study is case study which according to Caiderhead (2006) allows for an in-depth examination of events, phenomena, or other observations within a real-time context for purposes of investigations, theory development and testing, or simply as a tool for learning. Case study often employs documents, artefacts, interviews and observations during the course of research. Caiderhead, (2006) describe case study "types". These types are factual, 
interpretative and evaluative. Each case study must outline the purpose, then depending on the type of case study and the actions proposed by the researcher, the researcher could determine the possible products of the study.

\subsection{Population and Sampling}

The population comprised junior lecturers from one faculty at an institution of higher learning. The total population of this school was thirty three. Du Plooy (1997:48) refers to sampling as the rigorous procedures involved when selecting individuals from a large population. A sample is therefore a group of subjects chosen from the population using a particular sampling method. In the first phase of data collection an open-ended questionnaire was used. Thereafter, purposive sampling determined the number of respondents who were interviewed. The open-ended questionnaire was used to gather information on how lecturers practice self-reflection in different courses. Ten junior lecturers in one faculty were given open ended questionnaire to answer. Thereafter, the total of five junior lectures with less than five years teaching experience were interviewed on one on one interview.

\subsection{Data Collection and Instruments}

To carry out any type of research investigation, data must be gathered. Many different methods and procedures have been developed to aid in the acquisition of data. These procedures employ distinctive ways of collecting the data. Each is particularly appropriate for certain sources of data, yielding information of the kind and in the form that can be most effective (Kothari, 1997: 207). The use of various techniques allows the researcher to confirm the findings. For this study two phases were undertaken; phase 1: open-ended questionnaire; phase 2: one on one interview.

\subsubsection{Trustworthiness}

Trustworthiness is a set of quality criteria for judging interpretive research, which is also known as 'authenticity criteria' (Kolb, 1999:36). In this regard, qualitative research theorists advise researchers to explain what precautions they have taken to enhance the trustworthiness of the findings of their studies. Therefore, the researcher gave an overview of two trustworthiness criteria: credibility and transferability.

\subsubsection{Credibility}

The researcher has worked in the University for a period of five years; as a result he is familiar with the culture of this University. To ensure credibility of the results the researcher has done some consultations about self-reflection related activities before the actual data collection sessions. The researcher has also used random sampling in the first phase of data collection and purposive sampling in the second phase. Triangulation was also applied by using open-ended questionnaire, one on one and focused group interviews. To ensure honesty and guanine information, participants was given a chance to refuse to participate in the study, in other words the participation will be voluntary.

\subsubsection{Transferability}

All Universities in South Africa are expected to keep certain national and international standard. The transferability of credits across the Universities unified the curriculum and practice of teaching in higher institution. Therefore, the results of this can be transferred or applied in other universities, be it nationally or internationally.

\section{Data Analysis}

Davison (1997) states that data analysis is the process of making sense out of data, which involves consolidating, reducing and interpreting what has been said and what the researcher has seen and read. It is thus the process of understanding, making sense and meaning of the data. This understanding was organised into a descriptive account. Data collected from open-ended questionnaires was sorted and organised and speculated on in order to develop meaning from it. In this study, the taped recorded interviews were transcribed verbatim. After transcribing interviews, a sense of the whole was obtained by reading carefully with understanding and summarizing the salient aspects.

\section{Ethical Issues}

This concerns the importance of both accurately informing the respondents as to the nature of research and obtaining 
their written consent to participate (Babbie 2007:64). Coercion was not used to force participation and the respondents were allowed to terminate their involvement in the research at any time. Participation of the respondents was voluntary. The researcher also assured the respondents that the information they provided was only to be used for research purposes. Furthermore, they were promised that their names will not be disclosed and the questionnaires were answered in a private place with only the respondent and researcher present. Lastly, the researcher showed respect for the wellbeing of the participants and the right to self-determination.

According to Kolb (1999:33), the validity of the instrument produces accurate results or information. In supporting Kolb's idea the researcher ensured validity of the instruments to collect data; by using both open-ended questionnaires and interviews in data collection. The researcher used these two data collecting instruments in order to ensure the validity of the results as the data collected from one instrument was corroborated with the data from the other. Reliability provides consistency of the information. The researcher first piloted the instruments, which according to Taylor (2008:34), is to test if the instrument will address the problem. The researcher administered few questionnaires to lecturers from another school to confirm the reliability of them. Adjustments were made to the questionnaire thereafter. Lastly, the researcher got certificate of ethical clearance from the University before the study was conducted in the institution.

\section{Results/Findings}

When junior lecturers were asked how they reflect on your practice, they responded differently; and the following themes were identified:

- At the end of every lesson;

- After a problem has arisen;

- During the lesson;

- After lecturing hours;

- After assessment.

Participants were also asked if self-reflection help them as junior lecturer; and the themes identified from their responses are as follows:

Different lecturers mentioned that self-reflection give junior lectures a chance to:

- check what disturbs teaching process;

- Open their mind and think about learning and teaching process;

- Check student's progress;

- To check relevant resources to be used in their practice;

- How teaching and learning can be improved;

- Set achievable goals in their lecturing;

- To know students much better;

- Boast lecturer's confidence;

- To identify their strength and weaknesses;

- To check if they improve in their lecturing.

\section{Discussion of Findings}

When junior lecturers were asked the question about when do they reflect on their practice; they responded differently. Some have responded by saying that they reflect on their practice at the end of the lesson. It appears junior lecturer in this institution may not reflect on their practice while they teach, but only after the lesson. This reveals that if lecturers (junior) are applying or using the wrong teaching method that is not suitable for the lesson, they will continue to do so until the end of the lesson, since they only reflect at the end. The present study suggested that these lecturers should use reflective approaches that will help them reflect while they teach and even at the end of the lesson. Lecturers in this faculty further argued that they reflect only if the problem has arisen. This shows that they reflect only after the damage has already done. When the researcher further investigated the kind of problem that may lead this lecturers to reflect on their practice; they responded that in most cases they only reflect when students have failed. The present study further suggested junior lecturers to view self-reflection as a process that goes along with their teaching practice. Junior lecturers need to reflect on their practice on a daily basis, without waiting for a problem to happen first; and this will help them to grow professionally and it will also minimise some negative comments during evaluation of teaching and learning.

When junior lecturers were asked the question on how self-reflection helps them as teachers, they responded 
differently. Self-reflection helps them check things that disturb them during teaching process. Junior lecturers need to identify whatever that disturbs their teaching; and this will help them to know where improve in their practice. Whatsoever that disturbs teaching, junior lecturers should find a way of solving it. This may be done by setting course meetings to discuss the challenges they come across in their practice. Lecturer need to think critically about their teaching and need to open their mind in solving obstacles that disturbs their teaching. Reflective practitioner is a critical thinker that always strive a way of improving his practice, as a results self-reflection will help them in many ways.

Moreover, self-reflection also helps lecturers to open their minds and think about learning and teaching process. Teaching process involves how the lecturers teach their lessons and how students learn, so a good reflective practitioner will take students in to consideration when reflecting on their practice. The practice of self-reflection will therefore provide junior lecturers with opportunity to think about how students learn, and how best they can improve self-reflection in order to improve their practice, and minimize negative evaluation comments.

Junior lecturers also use self-reflection to check student's progress. By checking student's progress, one can be able to explain the kind of teaching that has taken place. There is a close relationship between student's progress and self-reflective practice. A good practice of self-reflection will results in to positive results of students. Students's progress will determine how best self-reflection was done.

\section{Conclusion}

Reflecting on the findings of this study one will realise that self-reflection is very important for junior lecturers, especially as a novice academics. Evaluation of teaching and learning becomes compulsory in the institution of higher learning; therefore junior lecturers can use self-reflection as a tool to reduce negative comments during evaluation of teaching and learning. What is important is that junior lecturers should see self-reflection as an ongoing tool that goes along with their teaching practice; as a result they will grow and improve as professionals.

\section{Recommendations}

The results of this study revealed that self-reflection is important for junior lecturer as beginners in the field of academic. Therefore, this study recommends that junior lecturers need to be trained and work-shopped about different reflective practice and its importance. Teaching practice takes place on a daily basis, therefore the study recommends that junior lecturers regard self-reflection as part of their daily activities and that the University should make it compulsory for junior lecturers as novice in the academic field. The study also found out that junior lecturers have different views and opinions about self-reflection; as a result they practice it differently. Therefore the study recommends that the faculty concerned should have a uniform/framework on how self-reflection should be practiced. A common understanding of self-reflection has an advantage of lecturers working together and helping each other to achieve a common goal, which is to improve their teaching practice and minimize negative comments during evaluation of teaching and learning.

\section{References}

Babbie, E. (2007). Teaching and Curriculum Methods in South Africa. Reflective Model 3 (1):223-443

Clarke, B.R. (1995). Quantitative research practice: A guide for social sciences students and research. JL Van Schaick: Pretoria.

Creswell, T. (1998). The teacher as self-observer. In Jack C. Richards, The Language Teaching Matrix. New York

Criticos, C. (2002). Getting Practical. 2nd edition. Oxford University of Press: Cape Town.

Davidson, J.W. (1997). Research design quantitative, qualitative and mixed methods. 2nd edition. Juta: Cape Town.

Devos, P.P. (2001). Ethically Based Model of Inquiry. 1st edition. Japan

Dewey, P.P. (1997). Ethically Based Model of Inquiry. 2nd edition. Butterworth. Durban.

Du Plooy, F. (1997). Reflection in higher education. 3rd edition. Juta: Cape Town.

Gibbs, G. (1998). Learning by doing: A guide to teaching and learning. London: FEU

Henderson, F.F. (1990). Theories of practice. A Reflective Teaching Model, 2 (1):243.

Kolb, D. (1999). Research Methodology. Basic concept in methodology of social sciences research. Blackwell Publisher: Britain.

Kothari, S.T. (1997). Understanding reflection and models. 2nd edition. Rox and Sons Publishers: Cape Town.

Kottkamp, R.O. (1990). Find Out How You Teach. Adelaide, Australia: National Curriculum Resource Centre Leedy, G. (2001). Understanding reflective models. 2nd edition, Oxford University Press.

Mouton, G.T., \& Marias, H.K. (1998). Understanding and Evaluating Educational Research. 3rd edition.Virginia.

Moustakas, L.O. (1994). Teacher development through reflective teaching. In J.C. Richards and D. Nunan (Eds). Second Language Acquisition.

Park, J.Y., \& Kastanis, L.S. (2009). Reflective learning through social network sites in design education. International Journal of Learning, 16(8), $11-22$.

Taylor, B.R. (2008). Participation and reflection in classroom. American Journal of preventative medicine, 26(5):419-455.

Van Der Westhuizen, P. (1999). Evaluation a practical guide for teachers. University of Missouri, Columbia

Zeicher, K., \& Liston, O. (2005). Teaching student teachers to reflect. HER, 57(1):22-44. 